\section{Feldspathic and Lithium Disilicate Onlays with a 2-Year Follow-Up: Split-Mouth Randomized Clinical Trial}

\author{
Guilherme de Siqueira Ferreira Anzaloni Saavedra (1); João Paulo \\ Mendes Tribst (1); Nathália de Carvalho Ramos (D); Renata Marques \\ de Melo (1); Vinícius Anéas Rodrigues (1)2; Gabriela Freitas Ramos (D); \\ Marco Antonio Bottino (i) 1
}

\begin{abstract}
The present study was a prospective, controlled, randomized, clinical shortterm trial aiming to evaluate the clinical performance of adhesively luted, lithium disilicate and feldspathic glass-ceramics onlays over a period up to 2 years. A total of 11 patients ( 7 female, 4 male; age range: $18-60$ years, mean age: 39 years) were selected for this study. Each patient received a maximum of two restorations per group in a split-mouth-design. LD: Eleven onlays, performed with lithium disilicate-based ceramic (IPS e.max CAD, Ivoclar Vivadent, Schaan, Liechtenstein), and FP: Eleven onlays, performed with feldspathic ceramic (Vita Mark II, Vita Zanhfabrik, Bad Säckingen). Recalls were performed at 2 weeks (baseline $=\mathrm{R} 1$ ), 1 year (R2) and 2 years (R3) after the cementation by three calibrated blinded independent investigators using mirrors, magnifying eyeglasses, probes and bitewing radiographs. The postoperative sensitivity, secondary caries, marginal integrity, marginal discoloration, color match, surface roughness, tooth integrity, and restoration integrity were evaluated. The Friedman test was used to determine if there was a statistically significant difference in time-to-time comparison of the parameters in the ceramics restorations. A total of $95.4 \%$ of the restorations were clinically acceptable at the 2-year recall, without a difference for any evaluation parameter for both ceramic materials. Based on the 2-year data, the CAD-CAM onlays manufactured with feldspathic and lithium-disilicate based ceramics showed similar clinical performance.
\end{abstract}

${ }^{1}$ Department of Dental Materials and Prosthodontics, São Paulo State University (UNESP), Institute of Science and Technology, São José dos Campos/SP, Brazil. Adress: Av. Eng. Francisco José Longo, $\mathrm{n}^{\circ}$ 777. Jardim São Dimas, 12245-000 - São José dos Campos, SP. Brazil.

${ }^{2}$ Department of Dental Materials and Proshodontics, Faculty of Pindamonhangaba (FUNVIC), Pindamonhangaba/SP, Brazil. Estrada Radialista Percy Lacerda, Estr. Mun. do Pinhão do Borba, Bairro - $\mathrm{n}^{\circ} 1000$, Pindamonhangaba - SP, 12412-825

Correspondence: João Paulo Mendes Tribst Adress: Av. Eng. Francisco José Longo, 777 - 12245-000. Jardim São Dimas, São José dos Campos - SP, Brazil. São Paulo Mailing address: joao.tribst@gmail.com

\title{
Introduction
}

Contemporary adhesive dentistry is based on a stable bond strength between the dental substrate and the restorative materials, mainly obtained after the development of resinous cements and bonding agents capable maintain an adequate bond strength in long-term period $(1,2)$. In this context, glass ceramics have not only gained space as indirect restorative materials due to their high bondability to the dental substrate, but also due to their capacity of mimicking the lost tissues (3), wear resistance (4) and elastic modulus close to that of enamel (5).

An array of ceramic materials are available on the market and the dentist may perform restorations with materials presenting the same clinical indication but with different mechanical, optical and adhesive properties6. Several in vitro studies are available comparing the factors which may influence the success of a treatment with ceramic materials $(2,5,7-9)$. All of them agree that these materials are inherently brittle and prone to mechanical failures and crack growths at high stress levels and that clinical trials should be conducted to corroborate their conclusions.

Two materials which have been widely investigated in vitro are the feldspathic and lithium disilicate glass ceramics. Both ceramics are highly aesthetic $(10,11)$ have glassy matrixes, are acid-etchable and promote similar adhesion to resin cement1. In addition, both materials can be processed by heat pressing or CAD/CAM milling (11). However, the literature is scarce regarding longitudinal data about both types of materials, but mainly about the performance of CAD-CAM milled lithium disilicate restorations.

Both materials can resist masticatory forces well $(12,13)$ in minimally invasive restorations. The differences in crystalline conformation and the need of firing for additional crystallization $(6,11,14)$ suggest that lithium disilicate should be a better choice in the long-term, while the feldspathic porcelain is a cheaper material with less number of laboratory steps. 
The feldspathic porcelain is composed by $56-64 \% \mathrm{SiO}_{2}, 20-23 \% \mathrm{Al}_{2} \mathrm{O}_{3}, 6-9 \% \mathrm{Na}_{2} \mathrm{O}, 6-8 \% \mathrm{~K}_{2} \mathrm{O}$; the flexural strength is $97 \mathrm{MPa}$ and 11.3 Weibull Modulus while the lithium disilicate based ceramic is composed by $58-80 \% \mathrm{SiO}_{2}, 11-19 \% \mathrm{Li}_{2} \mathrm{O}, 0-13 \% \mathrm{~K}_{2} \mathrm{O}, 0-8 \% \mathrm{ZrO}_{2}, 0-5 \% \mathrm{Al}_{2} \mathrm{O}_{3}$; presents a flexural strength calculated in $415 \mathrm{MPa}$ and 10.7 Weibull Modulus15. The difference in flexural strength, almost $4 \times$ higher between both materials is justified since the feldspathic ceramic material containing a weak glass matrix and irregularly shaped crystalline phases such as silica, potassium, and alumina, which are more brittle than a reinforced ceramic (15). This more prone to fail behavior reduces the data variability showing a higher Weibull modulus what means a higher reliability in strength. Therefore, the feldspathic porcelain presents a weaker structure, it requires a higher acid exposure time during surface etching due to the higher amount of silica content in comparison with lithium disilicate ceramic. Despite all the differences between both materials, they share several clinical indications and it is up to the dentist to choose which one should be used during the treatment planning.

Therefore, a clinical trial with a split-mouth set-up, comparing the performance of both materials would be useful to understand how they behave in the same patient and if the use of a stronger material as lithium disilicate would make a difference in the restoration longevity. To the authors's knowledge, this questions and study design have not been performed yet and this question cannot be answered properly. Thus, a prospective, controlled, randomized, clinical short-term trial was conducted with the aim to evaluate the clinical performance of adhesively-luted, lithium disilicate and feldspathic glassceramics onlays over a period up to 2 years. The null hypothesis was that there would be no difference between both materials performance, after the evaluated period.

\section{Materials and methods}

A total of 11 patients ( 7 female, 4 male; age range: 18-60 years, mean age: 39 years) were selected for this parallel study design with 1:1 allocation ratio according to the inclusion criteria summarized in Table 1. The study was designed as a prospective, controlled, randomized, clinical trial in a split-mouth design following the recommendations outlined by the American Dental Association (ADA) Acceptance Program Guidelines. Written informed consent was obtained from all participants included in the study. The local Ethical Committee (\#24839213000000077) of São Paulo State University, Institute of Science and Technology, Brazil approved the study. This clinical trial was registered in the Brazilian Clinical Trials Registry (ReBEC, \# RBR-5PDP82).

Table 1 - Inclusion and exclusion criteria.

\begin{tabular}{cl}
\hline \multicolumn{1}{c}{ Inclusion criteria } & \multicolumn{1}{c}{ Exclusion criteria } \\
\hline $\begin{array}{c}\text { Presence of caries lesion, defective amalgam or } \\
\text { composite restorations in posterior dentition } \\
\text { (molars), suitable for the restoration with } \\
\text { ceramic onlays. }\end{array}$ & Absence of caries lesion or reduced crown \\
Presence of antagonist tooth & Absence of antagonistic tooth \\
\hline Older than 18 years & Younger than 18 years \\
\hline Good general and oral health & Uncontrolled systemic impairment \\
\hline Absence of orthodontic appliances & Orthodontic appliances users \\
\hline Absence of malocclusion and tooth malformation & Presence of malocclusion and tooth \\
\hline Absence of non-carious cervical lesions & malformation \\
\hline Vital posterior teeth & Presence of non-carious cervical lesions \\
\hline Healthy/treated periodontal situation & Non-vital posterior teeth \\
\hline
\end{tabular}


The sample size was calculated assuming parametric hypothesis testing with a power of $80 \%$ and $10 \%$ significance level for a two-sided test, considering the previous reports of survival for both materials in 2-year evaluations (100\% Lithium disilicate glass-ceramic and 98\% feldspathic ceramic).

Eligible participants were all adults aged 18 or above, who met the eligibility criteria to receive at least two onlays. The study took place at the Post-Graduate prosthesis clinic of São Paulo State University (Unesp), Institute of Science and Technology, São José Dos Campos, Brazil, and was done by one expert clinician (faculty), assisted by post-graduate students. For allocation of the subjects, a computergenerated randomization was used (http://wwwquantitativeskills.com/sisa/calculations/randmiz.htm) and each prepared tooth was allocated into one group of glass ceramics. Thus, the materials were randomly assigned following simple randomization procedures regarding the treatment groups. Each patient received two posteriors adhesively cemented ceramic onlays.

A total of 22 onlay preparations (two materials, $n=11$ ) were performed, with 14 ceramic restorations being placed in mandibular first molars and eight ceramic restorations in maxillary first molars. Each patient received a maximum of two restorations per group in a split-mouth-design. LD: Eleven onlays, performed with lithium disilicate-based ceramic (IPS e.max CAD, Ivoclar Vivadent, Schaan, Liechtenstein), and FP: Eleven onlays, performed with feldspathic ceramic (Vita Mark II, Vita Zanhfabrik, Bad Säckingen) (Figure 1).

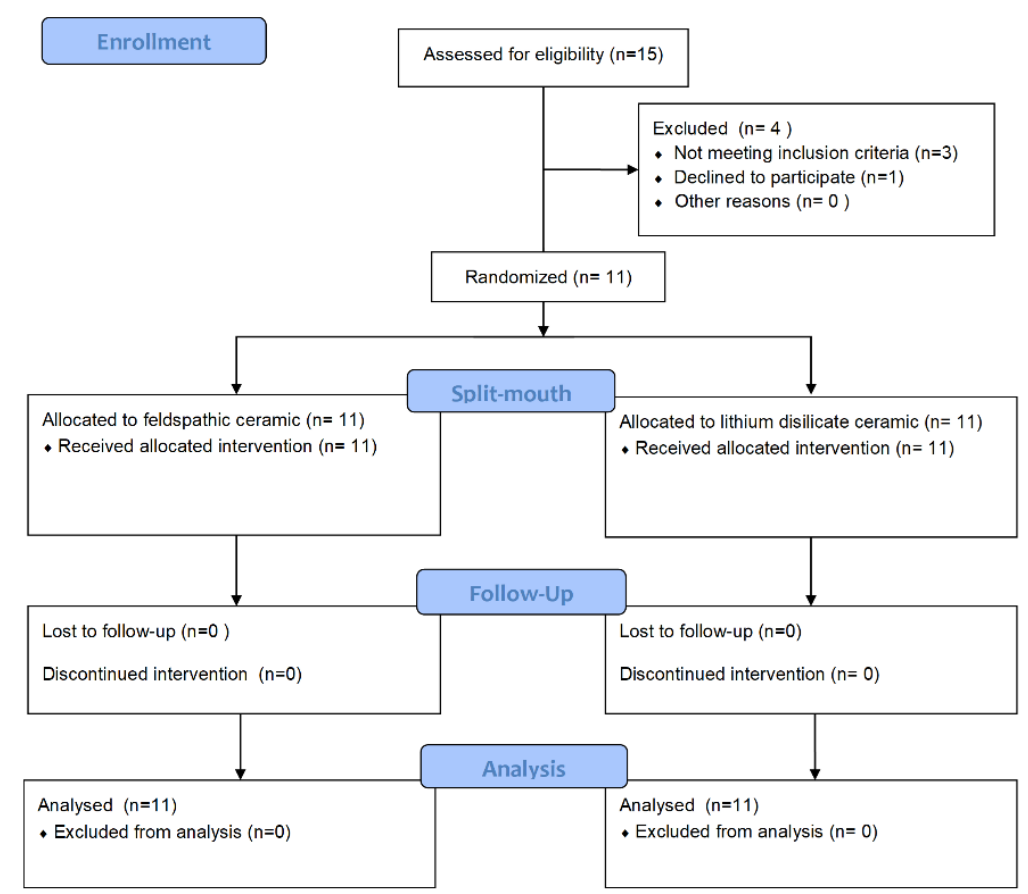

Figure 1 - CONSORT 2010 flow diagram for the present study.

The preparations for both groups were similar, performed by a blind operator, regardless of the restorative material. Preparations were performed using diamond burs (3200/3131/3131F KG Sorensen, Barueri, SP, Brazil) and finished with finishing diamond burs. The axial walls were slightly divergent without beveled margins. A minimum depth of $1.5 \mathrm{~mm}$ and an extension $2 \mathrm{~mm}$ at the isthmus and 1.5 $\mathrm{mm}$ tooth removal at the cusps (when cusp coverage was necessary) were generally performed. No lining or base material were used.

Full-arch impressions were performed using a polyvinyl-siloxane material (Virtual, Ivoclar Vivadent, Schaan, Liechtenstein) followed by the fabrication of a die cast model for each patient with respect to occlusion, articulation, and proximal contact points. Provisional restorations were fabricated with a bisacrylic provisional material (Systemp, Ivoclar Vivadent, Schaan, Liechtenstein). Pre-hybridization procedures were performed on the prepared tooth with ED Primer A + B bonding agent (Kuraray, Kurashiki, Japan), and the provisional crown was placed on the preparation after rubbing a small amount of bonding agent on the cementation surface and light curing for $40 \mathrm{~s}$. 
The allocation sequence was concealed from the operator enrolling and assessing participants in sequentially numbered, opaque, sealed and stapled envelopes. The random list was prepared by an investigator with no clinical involvement in the trial. A dentist not involved in the clinical part of the study received the die cast model and envelopes containing the information necessary only to mill the restorations (tooth numbers and restorative materials). A dental CAD/CAM system (CEREC 3D system, Sirona, Bensheim, Germany, Software version 16.0) was employed for the design and fabrication of the restorations. They were milled according to the assigned ceramic material for each case (Vita Mark II, Vita Zanhfabrik or IPS E.max CAD, Ivoclar Vivadent). After the milling process, the restorations for LD were crystallized in a ceramic oven (Programat EP5000, Ivoclar Vivadent) according to the manufacturer's recommendations. Both ceramic materials received a finishing technique with abrasive rubber tips (0310/0317 Exa-cerapol, Edenta, Switzerland). After finishing, the onlays were fitted in the die cast model and checked with respect to occlusion, articulation, and proximal contact points. This operator performed the ceramic surface etching with $5 \%$ hydrofluoric acid gel (HF; Vita Ceramics Etch, Vita Zanhfabrik) for 20s for the LD and 60s for the FP glass ceramic (1).

Another operator received the milled restorations for cementation from each patient with the information about the teeth and its respective onlay. The temporary restorations for each patient were removed and the tooth surface was cleaned. After placing the rubber dam, the ceramic onlays were checked in situ for accuracy and intraoral fit. Proximal contacts were assessed using waxed dental floss. The internal surface of the restorations was cleaned with distilled water in an ultrasonic bath (5 min) and received the silane-coupling agent (Clearfil Ceramic Primer, Kuraray, Kurashiki, Japan) and the solvent was evaporated with compressed air. Selective enamel etching was applied to the prepared tooth using $37 \%$ phosphoric acid gel (Total Etch, Ivoclar Vivadent) on the enamel margins surrounding the cavity. The acid was carefully rinsed off after $30 \mathrm{~s}$, taking care not to contaminate the dentin. Following these procedures, the ED Primer A + B (Kuraray, Kurashiki, Japan) was mixed and applied on the prepared tooth during $30 \mathrm{se}$. After, the surface was gently air-dried during 10 seconds for the solvent evaporation.

The resin cement (Panavia F 2.0, Kuraray Noritake, Kurashiki, Japan) were used as the luting agent, and the manufacturer's recommendations were followed for all cementation procedures. The cement was applied to the internal surface of the restoration and the restorations were kept under constant pressure during light-activated polymerization for 60s (Bluephase $N_{1}$ Ivoclar Vivadent, Liechtenstein) on the occlusal surface. The luting composite was covered with glycerol gel (Oxyguard II, Kuraray Noritake) before polymerization to prevent the formation of an oxygen inhibition layer. After curing, the luting areas were examined for defects and resin overhangs were removed. Proximal polishing was done with interdental diamond and polishing strips. Final polishing was performed using felt discs with diamond polishing paste (Astropol, Ivoclar Vivadent, Liechtenstein).

Staff members who obtained outcome measurements were not informed of the restoration assignment for each tooth. Screening operator and CAD/CAM operator who delivered the restoration did not take outcome measurements. All investigators, staff, and participants were kept masked to outcome measurements and trial results.

Clinical evaluation was performed by three calibrated dentists. The modified USPHS criteria (Table 2) was used for the clinical criteria during the evaluation (13). 
Table 2 - Modified United States public health service (USPHS) criteria for the clinical evaluation of ceramic onlays used in this study.

\begin{tabular}{|c|c|c|}
\hline Characteristic & Rating & Criteria \\
\hline \multirow{2}{*}{$\begin{array}{l}\text { Postoperative } \\
\text { sensitivity }\end{array}$} & Alpha & No postoperative sensitivity \\
\hline & Bravo & Postoperative sensitivity \\
\hline \multirow[t]{2}{*}{ Secondary caries } & Alpha & No evidence of caries contiguous with the margin of the restoration \\
\hline & Bravo & Caries evident contiguous with the margin of the restoration \\
\hline Marginal & Alpha & No discoloration on the margin between the restoration and the tooth structure \\
\hline Discoloration & Bravo & Discoloration on the margin between the restoration and the tooth structure \\
\hline \multirow[t]{3}{*}{ Surface texture } & Alpha & Smooth surface \\
\hline & Bravo & Slightly rough or pitted, can be refinished \\
\hline & Charlie & Rough, cannot be refinished \\
\hline \multirow[t]{4}{*}{ Marginal Integrity } & Alpha & No visible evidence of ditching along the margin \\
\hline & Bravo & $\begin{array}{l}\text { Visible evidence of ditching along the margin not extending to the dentin- } \\
\text { enamel junction }\end{array}$ \\
\hline & Charlie & Dentin is exposed along the margin \\
\hline & Delta & Restoration is mobile, fractured, or missing \\
\hline \multirow[t]{3}{*}{ Color Match } & Alpha & $\begin{array}{l}\text { No mismatch in color, shade, and translucency between restoration and } \\
\qquad \text { adjacent tooth structure }\end{array}$ \\
\hline & Bravo & $\begin{array}{l}\text { Mismatch between restoration and tooth structure within the normal range of } \\
\qquad \text { color, shade, and translucency }\end{array}$ \\
\hline & Charlie & $\begin{array}{l}\text { Mismatch between restoration and tooth structure outside the normal range of } \\
\qquad \text { color, shade, and translucency }\end{array}$ \\
\hline \multirow[t]{2}{*}{ Restoration Integrity } & Alpha & No evidence of fracture \\
\hline & Bravo & Evidence of fracture \\
\hline \multirow[t]{2}{*}{ Tooth integrity } & Alpha & No evidence of fracture \\
\hline & Bravo & Evidence of fracture \\
\hline
\end{tabular}

The primary endpoint with respect to restorations performance was measured from baseline to 24 weeks. The recalls were performed at 2 weeks (baseline $=R 1), 1$ year $(R 2)$ and 2 years (R3) after the cementation by three calibrated blinded independent investigators using mirrors, magnifying eyeglasses, probes and bitewing radiographs. Additional analyses were done on the postoperative sensitivity, secondary caries, marginal integrity, marginal discoloration, color match, surface roughness, tooth integrity, and restoration integrity. The marginal adaptation was evaluated with direct-view technique as well as tactile inspection using a probe (Table 3). Both groups are exemplified in figures 2 and 3. 
Table 3 - Modified USPHS criteria evaluation of onlay restorations at baseline, 1-year, and 2-year follow-up (number of restorations and USPHS criteria in percent).

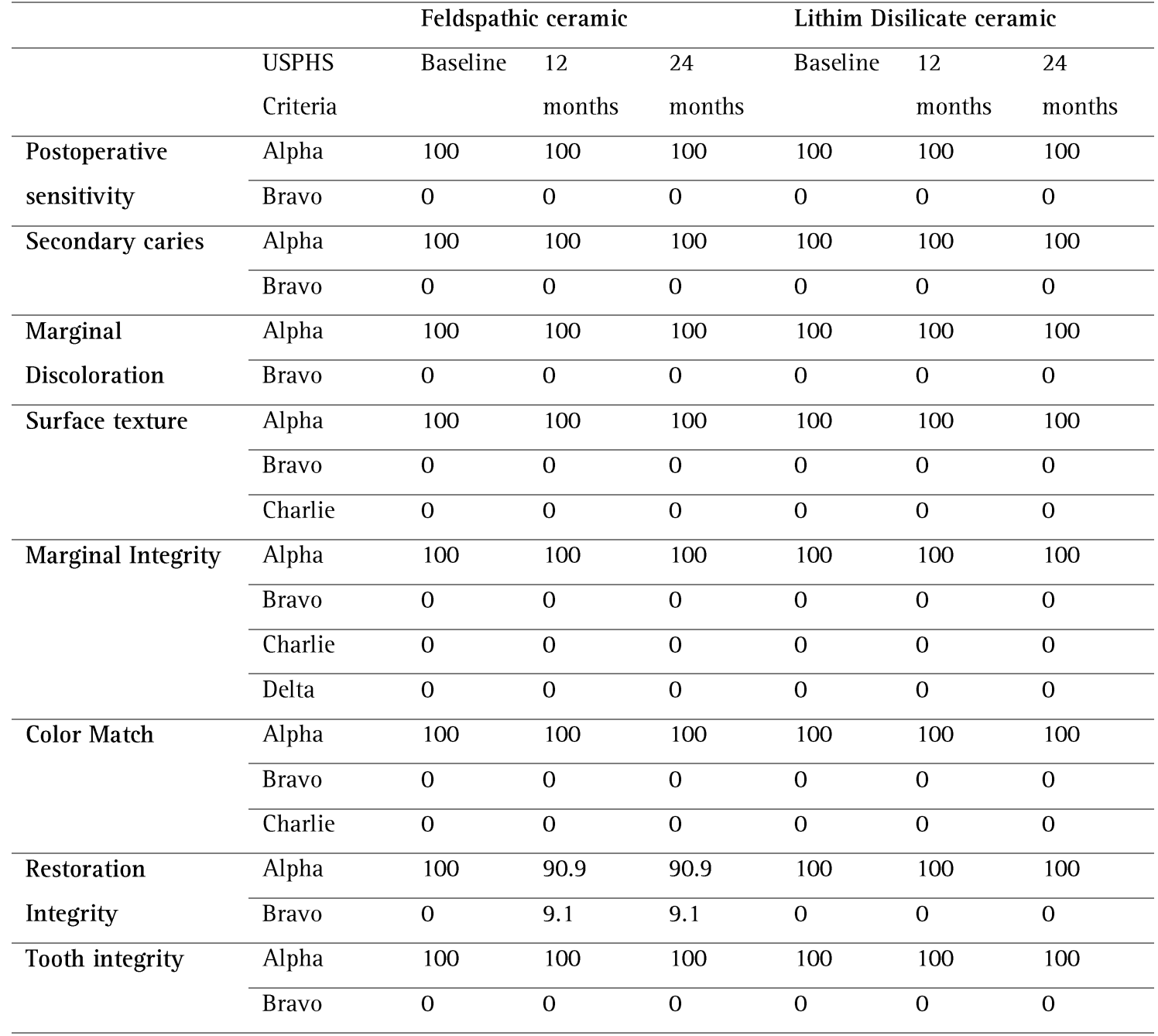

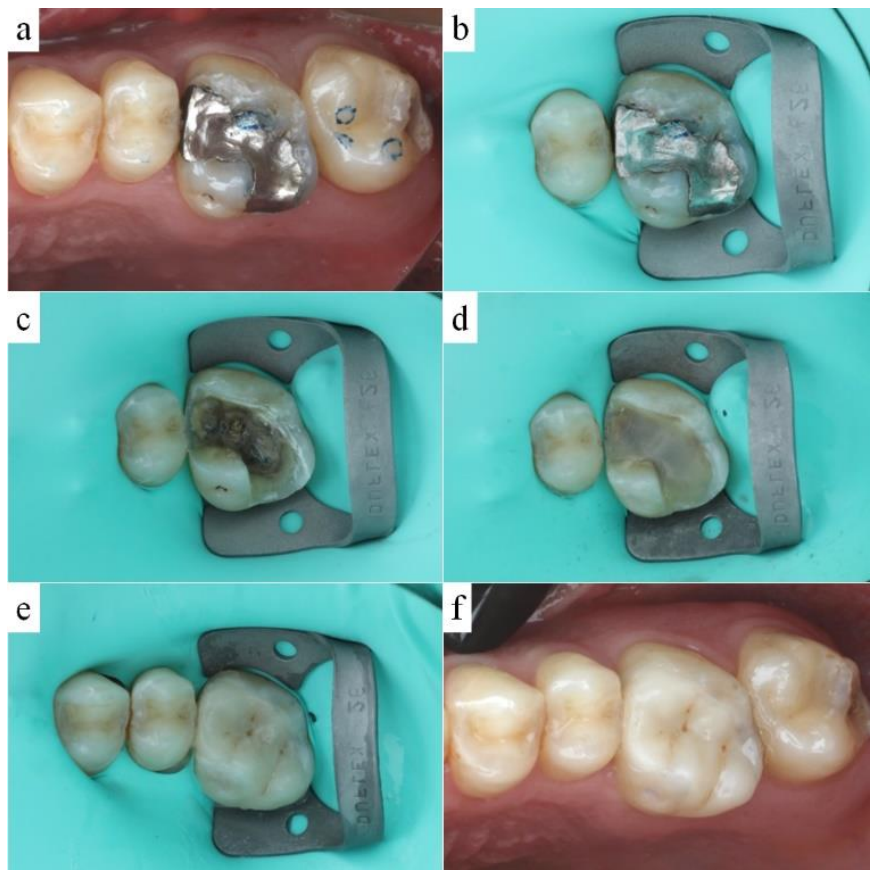

Figure 2(a-f) - Onlay performed using Feldspathic ceramic. (a) Clinical aspect of inadequate restoration, (b) rubber dam positioned, (c) cavity preparation, (d) cavity final shape, (e) cementation procedure and (f) final aspect.
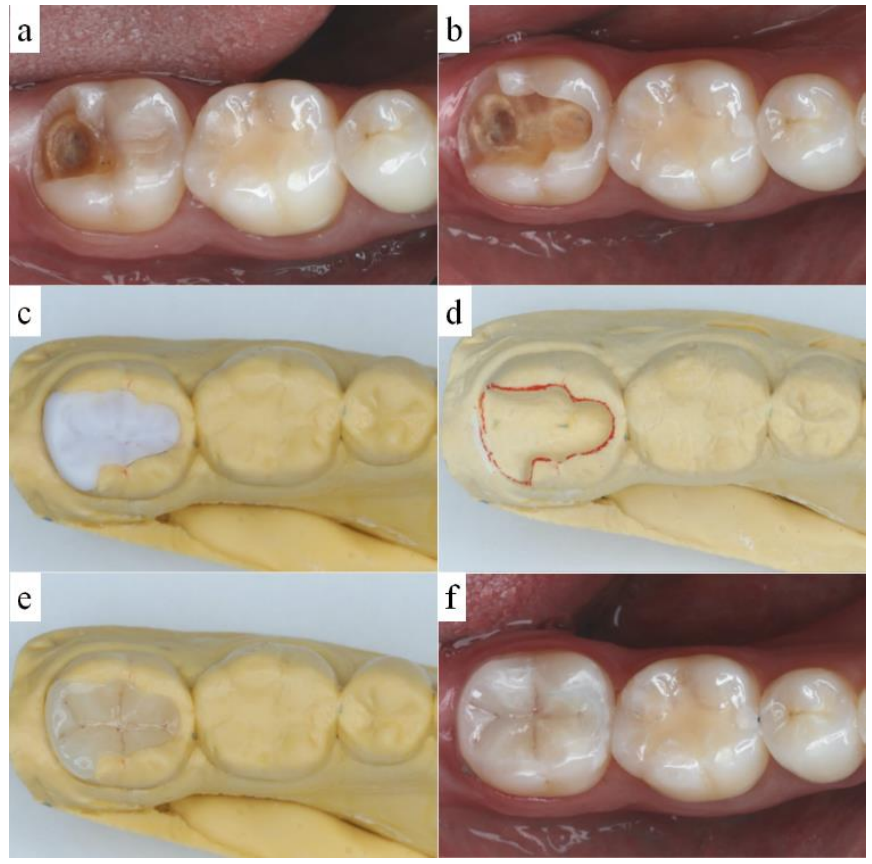

Figure 3(a-f) - Onlay performed using Lithium Disilicate ceramic. (a) Clinical aspect of inadequate restoration, (b) cavity preparation, (c) stone model with machined pre-crystalized onlay, (d) margin delimitation, (e) crystalized onlay (f) final aspect. 
All patients were asked a standardized questionnaire in order to investigate the occurrence and characteristics of postoperative sensitivity. The vitality of the restored teeth was tested. The statistical unit was the restoration.

A statistical software program (Minitab 16.1.0, State College, PA, USA) was used for the statistical analysis. Descriptive statistical methods of frequency, percentage, mean, and standard deviation were used to evaluate the study data. The study data was provided by 22 restorations. The results were evaluated at a $90 \%$ confidence interval and a significance level of $P<0.10$. The Friedman test was used to determine if there was a statistically significant difference in time-to-time comparison of the parameters in the LD and FP ceramics restorations.

\section{Results}

Eleven participants were considered in this study. Eligible participants were recruited from April 2017 to August 2017. 22 onlays were cemented in the posterior region. The recall rates at the first week, 1 year, and 2 years were $100 \%$, while $95.4 \%$ of the restorations were clinically acceptable at the 2-year recall. The trial was interruptedat the planned period. All patients who were randomly assigned were evaluated.

Regarding postoperative sensitivity, no statistically significant difference was found in either the Lithium Disilicate or the Feldspathic ceramic materials $(P=1.00)$. No secondary caries or endodontic complications were observed in the given recall periods.

The comparison of color, surface roughness, marginal discoloration, surface texture, marginal integrity and tooth integrity at baseline, 6 months, 1 year, and 2 years by groups showed no significant difference $(P=1.00)$. One restoration from the FP group scored Bravo for restoration integrity after 12 months, but no statistically significant difference was observed between either material $(P=0.966)$. The FP restoration with Bravo score showed a small crack near the margin and has been replaced following the described technical protocol however without blind operators.

\section{Discussion}

The aim of this prospective clinical study was to compare the clinical performance of ceramic onlays (LD and FP) manufactured by CAD-CAM at baseline, 1 year, and 2 years after cementation. The results of clinical follow-up criteria were found to be similar and clinically acceptable following a 2-year clinical follow up with LD and FP onlays, which were studied as a randomized split-mouth design.

The modified USPHS criteria is a reliable measurement standard for ceramic restorations, as previously reported $(13,15)$. A previous follow-up study of 10 years $(12)$ examined the performance of Feldspathic ceramic inlays and onlays in terms of clinical quality. A total of 200 restorations were adhesively bonded and the authors used the modified USPHS criteria to perform the clinical evaluation. The authors noted a success rate of feldspathic restorations which decreased to $90.4 \%$ after 10 years. A similar failure rate ( 8\%) of feldspathic inlays and onlays (16) was observed when larger (non-enamel margins) were considered. Regarding lithium disilicate, a two-year evaluation showed $100 \%$ survival (13), just as observed in the present study. Therefore, the previous findings tend to agree with ours, in which both types of materials behave similarly up to two years.

On the other hand, in vitro studies showed superiority in the mechanical behavior of lithium disilicate ceramics when compared to feldspathic ceramics (18). Compositional differences [feldspathic ceramic presented: SiO2 (59.5-65.5\%), Al2O3 (13-18\%), Na2O (4-8\%), K2O (10-14\%), other oxides (0$3.5 \%)$ and pigments $(0-2 \%)$; while the lithium disilicate glass ceramic presented: $\mathrm{SiO} 2(57.0-80.0 \%)$, Al2O3 (0.0-5.0\%), MgO (0.0-5.0\%), ZrO2 (0.0-8.0\%), P2O5 (0.0-11.0\%), ZnO (0.0-8.0\%), Li20 (11.0$19.0 \%)$, K20 (0.0-13.0\%), coloring oxides $(0.0-8.0 \%)$ and pigments $(0-2 \%)] 7$, and the presence of crystals and their orientations in the glass matrix may be responsible for the distinct mechanical behaviors. Thus, more clinical investigations with longer evaluation times regarding the survival of these CAD-CAM glass ceramics is warranted.

Both ceramic materials used to perform the restorations during the experimental design also present the same bond strength with resin cement in the short and long term (1). This is important to justify the lack of differences in marginal discoloration for both groups of materials, regardless of the evaluation period. 
A proper surface etching should be performed to achieve the adequate bond strength between restoration and cement (19). All restorations evaluated in the present study were cemented with selective enamel etching and a self-etching adhesive system. Regarding the surface treatment on each material, different HF exposure times were due to the differences in the amount of glassy phase present in the ceramic matrix (1).

In comparing the Immediate or Delayed Dentin Sealing in vital molar teeth during the preparation for partial ceramic restorations, a previous clinical trial concluded that adhesively-luted partial lithium disilicate ceramic restorations in vital molar teeth have a good prognosis (20). The present study performed immediate dentin sealing and corroborate the same prognosis for vital molars.

The principal advantage noted by the authors for FP partial restorations in comparison with LD group was the absence of the need to use a laboratory oven to perform an additional crystallization process. As the CAD/CAM facility was used to manufacture all restorations for both groups, the LD was machined in the blue pre-crystalized stage (metasilicate) to allow a soft machining process (21), thus achieving similar clinical longevity, while the feldspathic group then had the advantage of being produced faster.

A systematic review (17) was conducted comparing the survival rate of ceramic and indirect composite inlays, onlays, and overlays manufactured according to different methods (CAD/CAM, pressable, and stratified), in which the authors found that the CAD/CAM workflow showed a statistically highest survival rate (97\%) than the pressable technique (95\%) in the same period (5 years). The glass ceramic inlays, onlays, and overlays showed high survival rates and can be considered a safer treatment in comparison with composite restorations. This may also explain the high survival rate in all USPHS criteria evaluated herein. However, in this systematic review, the authors included glass ceramics and feldspathic porcelains in the CAD/CAM group, and only glass ceramics in the pressable group. Therefore, the present study can contribute with the comparison between both materials and confirm that the FP and LD present similar performances after a 2-year evaluation in the case of inlay/onlay machined restorations.

Another systematic review (22), found 95\% success-rate for single crowns in a period of 5-years for both feldspathic and LD ceramic restorations. The present study showed approximately $95 \%$ for feldspathic ceramic after only 2-years period. This shorter longevity must be related with the lower confident interval (90\%) in comparison with the systematic review parameter (95\%); also the present study evaluated partial preparations and not full-crowns as in the systematic review. For the present study, the preparation design was restricted to the lost dental tissue and not as a full-crown that provide extra retention to the restorative material.

Before the luting procedure, the restorations were cleaned in ultrasonic bath with distilled water. This procedure has been performed to assure cleanliness of the restoration, since the presence of contaminants in the adhesive interface can reduce the bond strength values and negatively affect the treatment longevity (23). Nowadays, different cleaning protocols are related in the literature and further studies evaluating them for different ceramic materials should be performed.

The split-mouth design provided a well-controlled clinical evaluation. Although the outcomes were more accurate than an experimental study, only two CAD-CAM materials were assessed13. Thus, the present ceramics and others can be studied in future studies and for a longer time. Regarding the aesthetic, previous reports asserted that the feldspathic ceramic is more translucent than lithium disilicate ceramic material (15). As the split-mouth study design provide both materials for the same patient, it was something to worry during the treatment acceptance or aesthetic perception by the patient. Therefore, the difference in translucency should be more relevant for anterior region or when metal post-and-core is present as substrate. In the present study, for posterior partial restorations cemented on healthy teeth, it was not possible to observe any difference between both materials.

For the present study, the sample size was enough to find a difference between the restorative materials, with $80 \%$ of power. However, observing the results after two years, the authors agree that a larger number of patients should be more accurate to provide a stronger estimation. Longer period of evaluation and larger number of patients are encouraged to provide a more reliable data. It is important to emphasize this study's limitations, since the sample size could be higher, the period is a short-term evaluation, the restorations present similar overall shape however individualized for each patient tooth, only two restorative materials were compared and the luting procedure with different adhesive systems and resinous cements could modify the restorations performance. 
Within the limitations of this study and based on the 2-year data, the CAD-CAM onlays manufactured with feldspathic and lithium-disilicate based ceramics showed similar clinical performance.

\section{Acknowledgments}

The authors are grateful to Ivoclar Vivadent for the donation of the impression materials and IPS e.Max CAD ceramic blocks and to Vita Zhanfabrick for the donation of Vita Mark II ceramic blocks.

\section{Resumo}

0 presente estudo é um estudo clínico prospectivo, controlado, randomizado e de longo curto prazo, com o objetivo de avaliar o desempenho clínico de restauraç ões adesivas cerâmica vitrea reforçada com dissilicato de lítio e cerâmica feldspática por um periodo de até 2 anos. Um total de 11 pacientes (7 mulheres, 4 homens; faixa etária: 18-60 anos, idade média: 39 anos) foram inseridas para este estudo. Cada paciente recebeu duas restaurações por grupo em um delineamento de boca dividida. LD: Onze onlays, realizados com cerâmica à base de dissilicato de lítio (IPS e.max CAD, Ivoclar Vivadent, Schaan, Liechtenstein); e FP: Onze onlays, realizados com cerâmica feldspática (Vita Mark II, Vita Zanhfabrik, Bad Säckingen). Os retornos foram realizados em 2 semanas (linha de base $=$ R1), 1 ano (R2) e 2 anos (R3) após a cimentação, por três investigadores independentes, cegos e calibrados, usando espelhos, óculos de aumento, sondas e radiografias interproximais. Foram avaliadas a sensibilidade pós-operatória, cárie secundária, integridade marginal, descoloração marginal, correspondência de cores, rugosidade da superficie, integridade dentária e integridade da restauração. 0 teste de Friedman (95\%) foi utilizado para determinar se havia uma diferença estatisticamente significante na comparação periódica dos parâmetros nas restaurações cerâmicas. Um total de $95,4 \%$ das restaurações estava clinicamente aceitável no retorno de 2 anos, sem diferença para qualquer parâmetro de avaliação para ambos os materiais cerâmicos. Com base nos dados de 2 anos, as restaurações CAD-CAM fabricados com cerâmica feldspática e à base de dissilicato de lítio apresentaram desempenho clínico semelhante 


\section{References}

1.Tribst J, Anami LC, Özcan M, Bottino MA, Melo RM, Saavedra G. Self-etching Primers vs Acid Conditioning: Impact on Bond Strength Between Ceramics and Resin Cement. Oper Dent. 2018:43(4):372-379. doi:10.2341/16-348-L

2. Tribst JPM, Dal Piva AMDO, Lopes GC, Borges ALS, Bottino MA, et al. Biaxial flexural strength and Weilbull characteristics of adhesively luted hybrid and reinforced CAD/CAM materials to dentin: effect of self-etching ceramic primer versus hydrofluoric acid etching. J Adhes Sci Technol. 2020 1-16.

3. Adolfi D, Tribst JPM, Adolfi M, Dal Piva AMO, Saavedra GSFA, Bottino MA. Lithium Disilicate Crown, Zirconia Hybrid Abutment and Platform Switching to Improve the Esthetics in Anterior Region: A Case Report. Clin Cosmet Investig Dent. 2020 Feb 19;12:31-40. doi: 10.2147/CCIDE.S234980. PMID: 32110113; PMCID: PMC7036665.

4. Lawson NC, Janyavula S, Syklawer S, McLaren EA, Burgess J0. Wear of enamel opposing zirconia and lithium disilicate after adjustment, polishing and glazing. J Dent. 2014;42(12):1586-1591. doi:10.1016/j.jdent.2014.09.008

5. Ferruzzi F, Ferrairo BM, Piras FF, Borges AFS, Rubo JH. Fatigue survival and damage modes of lithium disilicate and resin nanoceramic crowns. J Appl Oral Sci. 2019;27:e20180297. Published 2019 May 30. doi:10.1590/1678-7757-2018-0297

6. Dal Piva AMO, Tribst JPM, Borges ALS, et al. CAD-FEA modeling and analysis of different full crown monolithic restorations. Dent Mater. 2018;34(9):1342-1350.

7. Isik $E_{1}$ Toktamis H. TLD characteristic of glass, feldspathic and lithium disilicate ceramics. Luminescence. 2019;34(2):272-279. doi:10.1002/bio.3605

8. Dal Piva AMO, Tribst JPM, Werner A, Anami LC, Bottino MA, Kleverlaan CJ. Three-body wear effect on different CAD/CAM ceramics staining durability. J Mech Behav Biomed Mater. 2020;103:103579. doi:10.1016/j.jmbbm.2019.103579

10. Morimoto S, Rebello de Sampaio FB, Braga MM, Sesma N, Özcan M. Survival Rate of Resin and Ceramic Inlays, Onlays, and Overlays: A Systematic Review and Meta-analysis. J Dent Res. 2016;95(9):985-994. doi:10.1177/0022034516652848

11. Silva LHD, Lima E, Miranda RBP, Favero SS, Lohbauer U, Cesar PF. Dental ceramics: a review of new materials and processing methods. Braz Oral Res. 2017;31(suppl 1):e58. Published 2017 Aug 28. doi:10.1590/1807-3107BOR-2017.vol31.0058

12. Otto T, De Nisco S. Computer-aided direct ceramic restorations: a 10-year prospective clinical study of Cerec CAD/CAM onlays and onlays. Int J Prosthodont. 2002;15(2):122-128.

13. Coşkun E, Aslan YU, Özkan YK. Evaluation of two different CAD-CAM inlay-onlays in a splitmouth study: 2-year clinical follow-up. J Esthet Restor Dent. 2020;32(2):244-250. doi:10.1111/jerd.12541

14. Amesti-Garaizabal A, Agustín-Panadero R, Verdejo-Solá $B$, et al. Fracture Resistance of Partial Indirect Restorations Made With CAD/CAM Technology. A Systematic Review and Meta-analysis. J Clin Med. 2019;8(11):1932. Published 2019 Nov 9. doi:10.3390/jcm8111932

15. Sen N, Us YO. Mechanical and optical properties of monolithic CAD-CAM restorative materials. J Prosthet Dent. 2018;119(4):593-599. doi:10.1016/j.prosdent.2017.06.012

16. Krämer N, Frankenberger R. Clinical performance of bonded leucite-reinforced glass ceramic inlays and onlays after eight years. Dent Mater. 2005;21(3):262-271. doi:10.1016/j.dental.2004.03.009

17. Sampaio FBWR, Özcan M, Gimenez TC, Moreira MSNA, Tedesco TK, Morimoto S. Effects of manufacturing methods on the survival rate of ceramic and indirect composite restorations: A systematic review and meta-analysis. J Esthet Restor Dent. 2019;31(6):561-571. doi:10.1111/jerd.12555

18. Sotto-Maior BS, Carneiro RC, Francischone CE, Assis NMSP, Devito KL, Senna PM. Fatigue Behavior of Different CAD/CAM Materials for Monolithic, Implant-Supported Molar Crowns. J Prosthodont. 2019;28(2):e548-e551. doi:10.1111/jopr.12922

19. Peumans M, De Munck J, Van Landuyt K, et al. Two-year clinical evaluation of a self-adhesive luting agent for ceramic inlays. J Adhes Dent. 2010;12:151-161

20. van den Breemer CRG, Cune MS, Özcan M, Naves LZ, Kerdijk W, Gresnigt MMM. Randomized clinical trial on the survival of lithium disilicate posterior partial restorations bonded using immediate or delayed dentin sealing after 3 years of function. J Dent. 2019;85:1-10. doi:10.1016/j.jdent.2019.02.001

21. Fu L, Engqvist $H$, Xia W. Glass-Ceramics in Dentistry: A Review. Materials (Basel). 2020;13(5):1049. Published 2020 Feb 26. doi:10.3390/ma13051049 
22. Sailer I, Makarov NA, Thoma DS, Zwahlen M, Pjetursson BE. All-ceramic or metal-ceramic toothsupported fixed dental prostheses (FDPs)? A systematic review of the survival and complication rates. Part I: Single crowns (SCs) [published correction appears in Dent Mater. 2016 Dec;32(12 ):e389-e390]. Dent Mater. 2015;31(6):603-623. doi:10.1016/j.dental.2015.02.011

23. Moura DMD, Araújo AMM, Souza KB, Veríssimo AH, Tribst JPM, Souza ROAE. Hydrofluoric acid concentration, time and use of phosphoric acid on the bond strength of feldspathic ceramics. Braz Oral Res. 2020;34:e018. Published 2020 Mar 16. doi:10.1590/1807-3107bor-2020.vol34.0018 